\title{
Japanese system buries the individual researcher
}

\author{
The hierarchy ensures that young scientists' grants are absorbed into the lab's budget.
}

Sir - The Japanese government is wrestling with reform of its university system to enhance international competitiveness (see Nature 412, 364; 2001 and Nature 419, 875-876; 2002), including trying hard to promote the activities of young researchers by providing better financial support. For example, in fiscal year 2002, the Japan Society for the Promotion of Science (JSPS) boosted the value of special grants to researchers under the age of 37 by $50 \%$, and 8,500 young researchers, primarily university staff, each received $\$ U S 10,000$ on average. Nevertheless, the real issue is whether such grants are effectively distributed to the intended targets. In fact, a substantial amount of this investment is being diverted to other recipients.

In fiscal year 2002, the JSPS provided a research grant of $\$ 8,000$ to each of its 4,800 fellowship recipients, including 2,100 PhD students. The grant is supposed to be distributed directly to individuals to facilitate creativity. Nevertheless, most individual grants are absorbed into supervisors' budgets. Consequently, most young researchers cannot use their own funds as they choose.

It is difficult to find documentation of this practice. Although the JSPS applies strict rules for budget expenditure, and recipients must submit detailed accounting reports to the society, their supervisors tell them how to fill in the reports. This is what has happened to me and to almost all JSPS fellowship recipients with whom I have been in contact.

The core of the problem lies in the daikozasei or grand-laboratory system, a hierarchical pyramid in which a professor commands all members, including associate and assistant professors, postdocs and students. The system is found in some European countries (including Germany, from which Japan inherited it), but its feudalistic aspect has been reinforced in Japan. Experimental facilities usually belong to a grand lab rather than to a department, unlike the situation in the United States, where associate and assistant professors control their own labs and perform their own research, relying on departmental core facilities for the use of expensive instruments.

Under the grand-lab system, even young assistant and associate professors suffer from diversion of funds. I have heard from several recipients of JSPS grants that their funds were absorbed into their professors' budgets via abuse of financial reports. During a government meeting on the reform of competitive research funding held in April 2002, the then minister for science and technology policy, Koji Omi, pointed out that grand-lab professors often systematically acquire grants intended for associate and assistant professors, and that such customs interfere with the independence of young researchers.

Because young researchers in Japan are funded by the larger budget of the grand lab, they can never complain about an offending professor. This is a setback routinely experienced by most young researchers in Japan. The restrictive

\section{Early work on elephant gait not to be forgotten}

Sir - I was fascinated by the beautiful video analysis of elephants' gaits performed by J. R. Hutchinson et al. (Nature 422, 493-494; 2003) but surprised to find no mention of Etienne-Jules Marey, who pioneered an analysis of elephant motion, photographically, in 1887 (E. J. Marey \& C. Pagès, C. R. Acad. Sci. 105, 149-156; 1887).

It is true that Eadweard Muybridge had photographed elephants in motion a couple of years earlier, but he did not mark up the salient joints as Marey did, and so could not measure vertical movement at the hip or shoulder. Moreover, his use of a battery of 24 separate cameras could not provide a "chronophotograph", as Marey called it, of successive configurations superimposed on a single plate. (Marey secured this by using an ordinary camera with a slotted-disc shutter rotating behind the open lens.) Such photographs, and the diagrams that could be extracted from

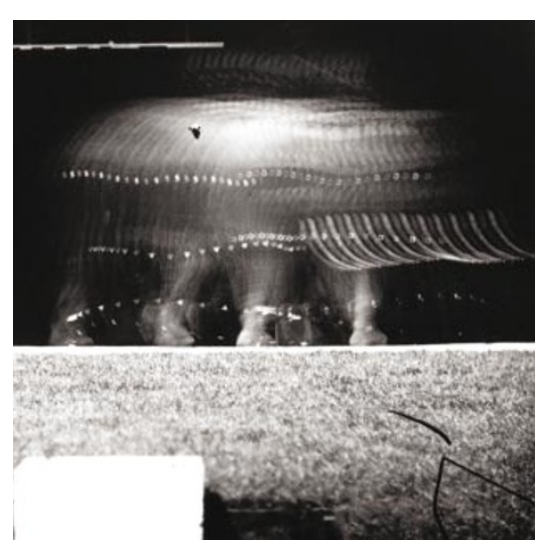

First steps: chronophotographs by EtienneJules Marey showed how elephants walked. academic structure of the grand-lab system wastes a substantial amount of investment in young scientists. The government's plan for promoting young researchers will not work effectively until a solution is found to the structural problems deeply rooted in Japanese academic research, where the individual is buried in the system.

Ippeita Dan

Science Communication Japan and

National Food Research Institute,

Tsukuba Science City 305-8642, Japan

dan@nfri.affrc.go.jp them, were necessary if one was to analyse the biomechanics involved.

Marey's elephants (see illustration) were marked in the same way as those of Hutchinson and colleagues. His motion analyses, which were far more probing and extensive than Muybridge's, are described very fully in Marta Braun's Picturing Time: The work of Etienne-Jules Marey, 1830-1904 (University of Chicago Press, Chicago, 1992).

\section{Oliver Sacks}

New York University School of Medicine, Psychiatry and Neurology, 2 Horatio Street 3G, New York, New York 10014, USA

\section{Making a song and dance about emotion}

Sir - The idea that dancing rids the body of nervous emotion was an old one even in 1953, as pointed out in ' 50 years ago' (Nature 422, 673; 2003).

Alfred Wallace, arguing against Darwin's notion of sexual selection in his book Darwinism (MacMillan, London \& New York; 1889), suggested that "the act of singing [by male birds] is evidently a pleasurable one and probably serves as an outlet for superabundant nervous energy and excitement, just as dancing, singing and field sports do for men".

A man of impeccable manners, Wallace - although not conceding a role for dance in the life of birds - concluded that "singing... may well have originated merely as... an invitation from the male to the female".

I await with nervous anticipation my invitation to Nature's next party.

Rupert C. Marshall

School of Biological Sciences, Royal Holloway,

University of London, Egham,

Surrey TW20 OEX, UK 